\title{
Twenty-year experience with the St Jude Medical mechanical valve prosthesis
}

John S. Ikonomidis, MD, PhD

John M. Kratz, MD

Arthur J. Crumbley III, MD

Martha R. Stroud, MS

Scott M. Bradley, MD

Robert M. Sade, MD

Fred A. Crawford, Jr, MD

From the Division of Cardiothoracic Surgery, Medical University of South Carolina, Charleston, SC.

Read at the Eighty-third Annual Meeting of The American Association for Thoracic Surgery, Boston, Mass, May 4-7, 2003.

Received for publication April 23, 2003; revisions requested June 4, 2003; revisions received June 27, 2003; accepted for publication July 7, 2003.

Address for reprints: John S. Ikonomidis, MD, PhD, Assistant Professor, Cardiothoracic Surgery, Medical University of South Carolina, Suite 409 CSB, 96 Jonathan Lucas Street, Charleston, SC 29464 (E-mail: ikonomij@musc.edu).

J Thorac Cardiovasc Surg 2003;126: 2022-31

Copyright (C) 2003 by The American Association for Thoracic Surgery

0022-5223/2003\$30.00+0

doi:10.1016/j.jtcvs.2003.07.005
Background: We have prospectively followed all adult St Jude Medical mechanical valve recipients at the Medical University of South Carolina since the initial implant in January 1979 and now present our 20-year experience.

Methods: We prospectively followed 837 valve recipients (aortic valve replacement; $\mathrm{n}=478$; mitral valve replacement; $\mathrm{n}=359$ ) from January 1979 to December 2000 at 12 -month intervals.

Results: Ages ranged from 19 to 84 years. Follow-up averaged (mean \pm standard deviation) $7 \pm 5$ years (98\% complete). Patients were in New York Heart Association class III or IV in $77 \%$ (aortic valve replacement) and $89 \%$ (mitral valve replacement) preoperatively. A $19-\mathrm{mm}$ valve was implanted in $15.5 \%$ of aortic valve replacement patients. Coronary bypass was required in $31 \%$ of aortic valve replacements and $20 \%$ of mitral valve replacements. Operative mortality was $17 / 478(3.6 \%)$ in aortic valve replacement and 19/359 (5.3\%) in mitral valve replacement, and multivariable predictors were $19-\mathrm{mm}$ valve size, 3 or more coronary bypass grafts, and New York Heart Association class IV for aortic valve replacement and New York Heart Association class IV and age for mitral valve replacement. Actuarial survivorship at 10 and 20 years was $57 \% \pm 3 \%$ and $26 \% \pm$ $5 \%$ for aortic valve replacement and $61 \% \pm 3 \%$ and $39 \% \pm 4 \%$ for mitral valve replacement. Multivariable predictors of late death were African-American ethnicity, New York Heart Association class III or IV, coronary bypass, and age for aortic valve replacement and New York Heart Association class III or IV, coronary bypass, and age for mitral valve replacement. For aortic valve replacement, effective orifice area was univariately $(P=.002)$ but not multivariately $(P=.378)$ predictive of late death. Structural valve deterioration was not observed. For aortic valve replacement, actuarial freedom (at 10 and 20 years) from reoperation was $93 \% \pm$ $1 \%$ and $90 \% \pm 2 \%$; thromboembolism, $82 \% \pm 3 \%$ and $68 \% \pm 8 \%$; bleeding events, $77 \% \pm 3 \%$ and $66 \% \pm 6 \%$; prosthetic valve endocarditis, $94 \% \pm 1 \%$ and $94 \% \pm 1 \%$; valve-related mortality, $94 \% \pm 2 \%$ and $86 \% \pm 4 \%$; and valve-related mortality or morbidity, $58 \% \pm 3 \%$ and $32 \% \pm 8 \%$. For mitral valve replacement, actuarial freedom (at 10 and 20 years) from reoperation was $96 \% \pm 1 \%$ and $90 \%$ $\pm 3 \%$; thromboembolism, $77 \% \pm 3 \%$ and $59 \% \pm 7 \%$; bleeding events, $86 \% \pm 2 \%$ and $65 \% \pm 8 \%$; prosthetic valve endocarditis, $98 \% \pm 1 \%$ and $96 \% \pm 2 \%$; valve-related mortality, $89 \% \pm 0.2 \%$ and $74 \% \pm 8 \%$; and valve-related mortality or morbidity, $63 \% \pm 3 \%$ and $29 \% \pm 7 \%$.

Conclusions: After 2 decades of observation with close follow-up, the St Jude Medical mechanical valve continues to be a reliable prosthesis. 




he St Jude Medical mechanical valve prosthesis (St Jude Medical Inc, St Paul, Minn) is a low-profile bileaflet mechanical valve constructed of pyrolytic carbon. The central flow design was originally believed to offer a lower transvalvular gradient compared with other mechanical valves, and its construction suggested that it would be durable and thromboresistant. These attributes have been largely substantiated by early, intermediate, and late reports of the use of this valve. ${ }^{1-10}$ Patients of the Medical University of South Carolina who have undergone valve replacement with the St Jude Medical mechanical prosthesis have been prospectively enrolled in an ongoing study since a clinical trial of this valve was initiated in January of 1979 . We have previously reported a 4-year, ${ }^{1}$ 10 -year, ${ }^{2}$ and 15 -year $^{7}$ experience in 1984, 1992, and 1999 , respectively. This report summarizes our 20-year experience with a consecutive series of recipients. During this period, approximately $48 \%$ of the adults undergoing valve replacement in our institution received tissue valves. This report considers only adult patients who have undergone isolated atrial valve replacement (AVR) or mitral valve replacement (MVR) with or without coronary bypass grafting, and the series does not consider patients undergoing combined valve procedures.

\section{Patients and Methods \\ Patients}

Between January of 1979 and December of 2000, 837 patients underwent either isolated AVR (478 patients) or MVR (359 patients) with the St Jude Medical mechanical valve prosthesis. The preoperative and intraoperative characteristics of the AVR and MVR cohorts are given in Table 1. All patients undergoing valve replacement at the Medical University of South Carolina since 1979 were entered prospectively into a computer database and were followed up on an annual basis either at this hospital or by the referring physician. In addition, written questionnaires were sent yearly to all patients. If the questionnaires were not returned or the patient reported an adverse event for which further details were required, telephone or personal interviews were conducted. Sixteen patients were lost (11 AVR, $5 \mathrm{MVR}$ ); therefore, follow-up was $98 \%$ complete overall. In the AVR group, follow-up was $98 \%$ complete and ranged from 1 month to 21 years (mean $7 \pm 5$ years), representing a total of 3212 patient years. In the MVR group, follow-up was $99 \%$ complete and ranged from 1 month to 20 years (mean $7 \pm 6$ years), representing a total of 2536 years. Morbidity and mortality were stringently defined according to the published guidelines of the Society of Thoracic Surgeons and The American Association for Thoracic Surgery. ${ }^{11}$

Operative techniques were similar to those published in prior reports. ${ }^{1,2,7}$ Briefly, standard cardiopulmonary bypass was established using disposable bubble or membrane oxygenator and moderate hypothermia $\left(26^{\circ} \mathrm{C}\right.$ to $\left.32^{\circ} \mathrm{C}\right)$. Cold crystalloid or blood cardioplegia was used for myocardial protection according to surgeon preference. An increasing tendency toward the use of retrograde blood cardioplegia was observed in later years. After debriding the
TABLE 1. Patient demographics

\begin{tabular}{|c|c|c|}
\hline Variable & AVR & MVR \\
\hline Total number & 478 & 359 \\
\hline \multicolumn{3}{|l|}{ Age (years) } \\
\hline Range & $20-84$ & $19-82$ \\
\hline Mean $\pm S D$ & $56 \pm 15$ & $53 \pm 13$ \\
\hline \multicolumn{3}{|l|}{ Sex } \\
\hline Male & $335(70 \%)$ & $145(40 \%)$ \\
\hline Female & $143(30 \%)$ & $214(60 \%)$ \\
\hline \multicolumn{3}{|l|}{ Etiology } \\
\hline Rheumatic & $73(15 \%)$ & $157(44 \%)$ \\
\hline Endocarditis & $35(7 \%)$ & $23(6 \%)$ \\
\hline Calcific & $248(52 \%)$ & $21(6 \%)$ \\
\hline Reoperative & $34(7 \%)$ & $43(12 \%)$ \\
\hline Ischemic & $0(0 \%)$ & $39(11 \%)$ \\
\hline Degenerative & $44(9 \%)$ & $67(19 \%)$ \\
\hline Congenital & $42(9 \%)$ & $6(2 \%)$ \\
\hline Other & $2(0.4 \%)$ & $3(1 \%)$ \\
\hline \multicolumn{3}{|l|}{ Lesion } \\
\hline Stenosis & $261(55 \%)$ & $97(27 \%)$ \\
\hline Insufficiency & $154(32 \%)$ & $222(62 \%)$ \\
\hline Combined & $63(13 \%)$ & $40(11 \%)$ \\
\hline \multicolumn{3}{|l|}{ Valve sizes $(\mathrm{mm})$} \\
\hline 19 & $74(16 \%)$ & 0 \\
\hline 21 & $123(26 \%)$ & 0 \\
\hline 23 & $140(29 \%)$ & $3(1 \%)$ \\
\hline 25 & $78(16 \%)$ & $8(2 \%)$ \\
\hline 27 & $47(10 \%)$ & $49(14 \%)$ \\
\hline 29 & $11(2 \%)$ & $134(37 \%)$ \\
\hline 31 & $4(0.8 \%)$ & $104(29 \%)$ \\
\hline 33 & $1(0.2 \%)$ & $61(17 \%)$ \\
\hline Associated CABG & $150(31 \%)$ & $72(20 \%)$ \\
\hline \multicolumn{3}{|l|}{ Preoperative NYHA } \\
\hline \multicolumn{3}{|l|}{ class } \\
\hline I & $24(15 \%)$ & $12(3 \%)$ \\
\hline II & $85(18 \%)$ & $28(8 \%)$ \\
\hline III & $236(49 \%)$ & $166(46 \%)$ \\
\hline IV & $133(28 \%)$ & $153(43 \%)$ \\
\hline Operative mortality & $17(3.6 \%)$ & $19(5.3 \%)$ \\
\hline Patient follow-up (years) & $7 \pm 5$ & $7 \pm 6$ \\
\hline Lost to follow-up & $11(2 \%)$ & $5(1 \%)$ \\
\hline
\end{tabular}

NYHA, New York Heart Association; $C A B G$, coronary artery bypass grafting; $S D$, standard deviation.

valve annulus, the prosthesis was secured using interrupted sutures of 2-O Dacron reinforced with Teflon pledgets. Sutures were carefully placed from above and through the annulus so that the valve annulus would be everted when the sutures were tied, thus inserting the prosthesis in an intra-annular position. Beginning in 1988, the subvalvular apparatus of the mitral valve was preserved whenever technically feasible. Valve sizes for the 2 groups ranged from 19 to $33 \mathrm{~mm}$ (Table 1).

In the AVR group, the standard St Jude Medical mechanical prosthesis was used in 378 patients. The Masters series valve was used in 78 patients and the Hemodynamic plus valve was used in 22 patients. In the MVR group, the standard St Jude Medical prosthesis was used in 266 patients and the Masters series valve was used in 93 patients. Thirty-three patients received AVR with valve sewing rings impregnated with Silzone, as did 37 patients undergoing MVR. 
TABLE 2. Factors associated with operative and late death

\begin{tabular}{|c|c|c|c|c|}
\hline Variable & Univariate $P$ value & Multivariate $P$ value & Odds ratio & $95 \% \mathrm{CL}$ \\
\hline \multicolumn{5}{|l|}{ Operative death } \\
\hline \multicolumn{5}{|l|}{ Aortic valve replacement } \\
\hline Valve size $19 \mathrm{~mm}$ & .003 & .041 & 3.81 & $1.36,10.65$ \\
\hline CABG $\geq 3$ vessels & .048 & .041 & 3.55 & $1.06,11.94$ \\
\hline NYHA class IV & .019 & .039 & 2.86 & $1.05,7.79$ \\
\hline \multicolumn{5}{|l|}{ Mitral valve replacement } \\
\hline Preop NYHA class IV & .005 & .022 & 3.48 & $1.19,10.14$ \\
\hline Increased age & .013 & .039 & 1.05 & $1.00,1.09$ \\
\hline \multicolumn{5}{|l|}{ Late death } \\
\hline \multicolumn{5}{|l|}{ Aortic valve replacement } \\
\hline African-American race & .023 & $<.0005$ & 2.49 & $1.73,3.60$ \\
\hline NYHA class III or IV & $<.0005$ & .001 & 2.25 & $1.42,3.55$ \\
\hline Associated CABG & $<.0005$ & .002 & 1.69 & $1.22,2.33$ \\
\hline Increased age & $<.0005$ & $<.0005$ & 1.04 & $1.03,1.05$ \\
\hline \multicolumn{5}{|l|}{ Mitral valve replacement } \\
\hline NYHA class III or IV & .016 & .015 & 3.04 & $1.24,7.46$ \\
\hline Associated CABG & .001 & .047 & 1.60 & $1.01,2.55$ \\
\hline Increased age & $<.0005$ & .002 & 1.03 & $1.01,1.04$ \\
\hline
\end{tabular}

NYHA, New York Heart Association; CABG, coronary artery bypass grafting.

Heparin administration was started (5000 units subcutaneously every 6-12 hours depending on the surgeon preference) on the first postoperative day and continued until prothrombin time or more recently the International Normalized Ratio (INR) was regulated with the administration of warfarin sodium. Early in our experience, the INR was maintained at 2.5 to 3.5. More recently, we have recommended a target INR of 2.0 for patients who have undergone AVR and 2.0 to 2.5 for MVR. The warfarin dose was regulated by the surgeon during hospitalization and during early follow-up and thereafter by the referring physician.

\section{Statistical Analysis}

Continuous variables are reported as the mean \pm 1 standard deviation and the categorical variables are represented as percentages. Actuarial curves were constructed to describe mortality and the incidence of valve-related complications using the KaplanMeier technique and are reported with the standard error of the mean. ${ }^{12-14}$ Because actuarial analysis is known to overestimate the incidence of nonfatal end points, "actual" or cumulative incidence curves were constructed for both the AVR and MVR groups for the end points of reoperation, endocarditis, thromboembolic events, and anticoagulation-related hemorrhage. ${ }^{15}$ Linearized rates, used to describe multiple events, were reported as \%/patientyear and those reported for the Silzone valve subset were compared to the remainder of the valve cohort using the exact binomial test. Independent factors associated with operative and late death were identified using logistic regression ${ }^{16}$ and the Cox proportional hazards regression model, ${ }^{17}$ respectively. Variables used for both the AVR and MVR groups are summarized in the Appendix. Effective orifice areas (EOAs) used for analysis were kindly provided by St Jude Medical, Inc.

\section{Results}

Survival

In the AVR cohort there were 17 operative and 173 late deaths (37 valve-related, 63 cardiac, 44 noncardiac, 29 sudden/unknown). In the MVR group there were 19 operative and 117 late deaths ( 2 valve-related, 54 cardiac, and 64 noncardiac). Cox regression analysis showed that valve size of $19 \mathrm{~mm}$, coronary artery bypass grafting (CABG) of more than 3 vessels, and New York Heart Association (NYHA) class IV were independent predictors of operative death in the AVR cohort. EOA and the EOA index did not emerge as independent predictors of operative mortality. Preoperative NYHA class IV and increased age were predictors for operative death in the MVR cohort (Table 2). Actuarial survivorship (Figure 1) at 10 and 20 years was $57 \% \pm 3 \%$ and $26 \% \pm 5 \%$ (AVR) and $61 \% \pm 3 \%$ and $39 \% \pm 4 \%$ (MVR). Cox analysis showed that independent predictors of late death in the AVR group were African-American ethnicity, NYHA class III or IV, concomitant coronary bypass, and increasing age. EOA was univariately $(P=.002)$ but not multivariately $(P=.378)$ predictive of late death. Independent predictors of late death following MVR were NYHA class III or IV, concomitant CABG, and increased age (Table 2).

\section{Reoperation}

Reoperation was performed for 29 patients in the AVR cohort and 15 patients in the MVR cohort. Reasons for reoperation in the AVR cohort were perivalvular dehiscence in 5 patients, endocarditis in 19 patients, and other causes in 5. Reasons for reoperation in the MVR group were perivalvular dehiscence in 7 patients, prosthetic valve endocarditis in 6 patients, and other causes in 2 patients. Structural valve deterioration was not seen in either the AVR or MVR group. Actuarial and cumulative incidence freedom from reoperation is given in Figure 2. In the AVR group, actuarial freedom from reoperation was $93 \% \pm 1 \%$ and $90 \% \pm 2 \%$ 


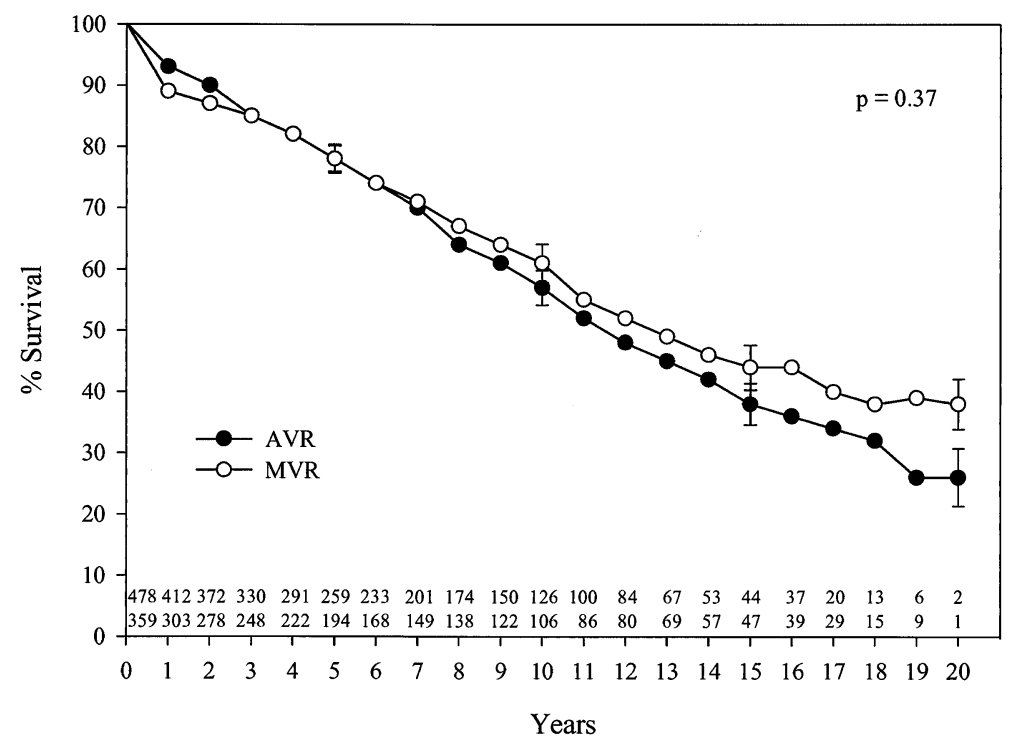

Figure 1. Actuarial survival after AVR and MVR.



Figure 2. Actuarial and "actual" freedom from reoperation after AVR and MVR.

at 10 and 20 years. Actual freedom was $94 \% \pm 1 \%$ and $92 \%$ $\pm 1 \%$ at 10 and 20 years. In the MVR group actuarial freedom from operation was $96 \% \pm 1 \%$ and $90 \% \pm 3 \%$ at 10 and 20 years. Cumulative incidence percentages were $95 \% \pm 1 \%$ and $93 \% \pm 2 \%$ at 10 and 20 years.

\section{Thromboembolic Complications}

In the AVR group, thromboembolism occurred in 54 patients (64 events total). Of these 33 were defined as strokes (10 were fatal) and 21 as transient cerebral ischemic attacks.
Three patients had peripheral embolic events (1 was fatal) and 7 patients had valve thrombosis ( 2 were fatal). Thromboembolism occurred in 61 patients in the MVR group (87 events total). Of these, 56 were defined as strokes (10 were fatal) and 23 as transient ischemic attacks. Five patients had peripheral embolic events and 3 patients had valve thrombosis.

Kaplan-Meier analysis showed the 10- and 20-year freedom from thromboembolic events to be $82 \% \pm 3 \%$ and $68 \% \pm 8 \%$ in the AVR group and $77 \% \pm 3 \%$ and $59 \% \pm$ 


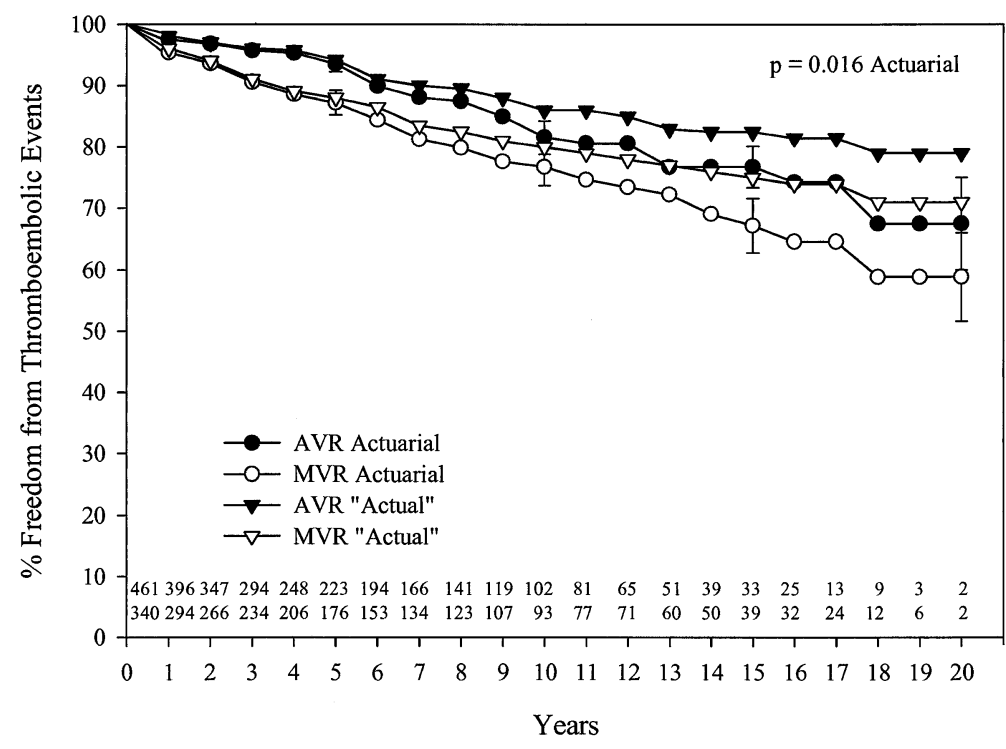

Figure 3. Actuarial and "actual" freedom from thromboembolic events after AVR and MVR.

$7 \%$ in the MVR group. Cumulative incidence analysis showed 10- and 20-year freedom from thromboembolic events to be $86 \% \pm 2 \%$ and $79 \% \pm 3 \%$ in the AVR group and $80 \% \pm 3 \%$ and $71 \% \pm 4 \%$ in the MVR group. Actuarial and cumulative incidence freedom from thromboembolic events is shown in Figure 3.

\section{Bleeding Events}

Major bleeding events occurred in 80 patients in the AVR group and 45 patients in the MVR group. Actuarial freedom from bleeding complications was $77 \% \pm 3 \%$ and $66 \% \pm$ $6 \%$ at 10 and 20 years in the AVR group and $86 \% \pm 2 \%$ and $65 \% \pm 8 \%$ in the MVR group. Cumulative incidence analysis showed freedom from bleeding events to be $80 \% \pm$ $2 \%$ and $75 \% \pm 3 \%$ in the AVR group at 10 and 20 years and $87 \% \pm 2 \%$ and $77 \% \pm 4 \%$ in the MVR group at 10 and 20 years. Actuarial and cumulative incidence freedom from bleeding events is shown in Figure 4.

\section{Prosthetic Valve Endocarditis}

Prosthetic valve endocarditis (PVE) occurred in 25 AVR patients and 7 MVR patients. After 4 years of follow-up, no cases of PVE were seen in the AVR group and only 2 cases were seen in the MVR group. For AVR, actuarial and cumulative incidence freedom from PVE was $94 \% \pm 1 \%$ and $94.3 \%$ at both 10 and 20 years. For MVR actuarial freedom from PVE was $98 \% \pm 1 \%$ and $96 \% \pm 2 \%$ at 10 and 20 years $(P=.02$ from AVR), with cumulative incidence estimates being $98 \%$ and $97 \%$ at 10 and 20 years.

\section{Valve-Related Mortality}

In the AVR cohort, 37 patients died of valve-related causes: embolism in 11 patients, valve thrombosis in 2 patients, bleeding events in 13 patients, prosthetic endocarditis in 6 patients, death related to reoperation for valve re-replacement in 4 patients, and death related to catheterization for perivalvular leak in 1 patient. In addition, 29 patients died of unknown causes. In the MVR group, 21 patients died of valve-related causes. These were due to embolism in 10 patients, bleeding events in 8 patients, prosthetic endocarditis in 2 patients, and death related to reoperation for valve re-replacement in 1 patient. Twelve patients died of unknown causes.

Kaplan-Meier analysis showed freedom from valve-related deaths to be $94 \% \pm 2 \%$ and $86 \% \pm 4 \%$ at 10 and 20 years in the AVR group and $89 \% \pm 2 \%$ and $74 \% \pm 8 \%$ at 10 and 20 years in the MVR group. Actuarial freedom from valve-related mortality is given in Figure 5.

\section{Valve-Related Mortality or Morbidity}

In the AVR cohort, 151 patients had valve-related morbidity or death. At 10 and 20 years, freedom from valve-related mortality or morbidity was $58 \% \pm 3 \%$ and $32 \% \pm 8 \%$, respectively. In the MVR group, 109 patients had valverelated morbidity or death. At 10 and 20 years, freedom from valve-related mortality or morbidity was $63 \% \pm 3 \%$ and $29 \% \pm 7 \%$, respectively. Freedom from valve-related mortality or morbidity in the AVR and MVR groups is given in Figure 5.

\section{Valve Prostheses with Silzone-Impregnated Sewing Rings}

A total of 70 patients received valve prostheses with Silzone-impregnated sewing rings between May 1998 and December 1999 and were followed for a total of 111 patient-years. Analysis of the Silzone subset compared with 


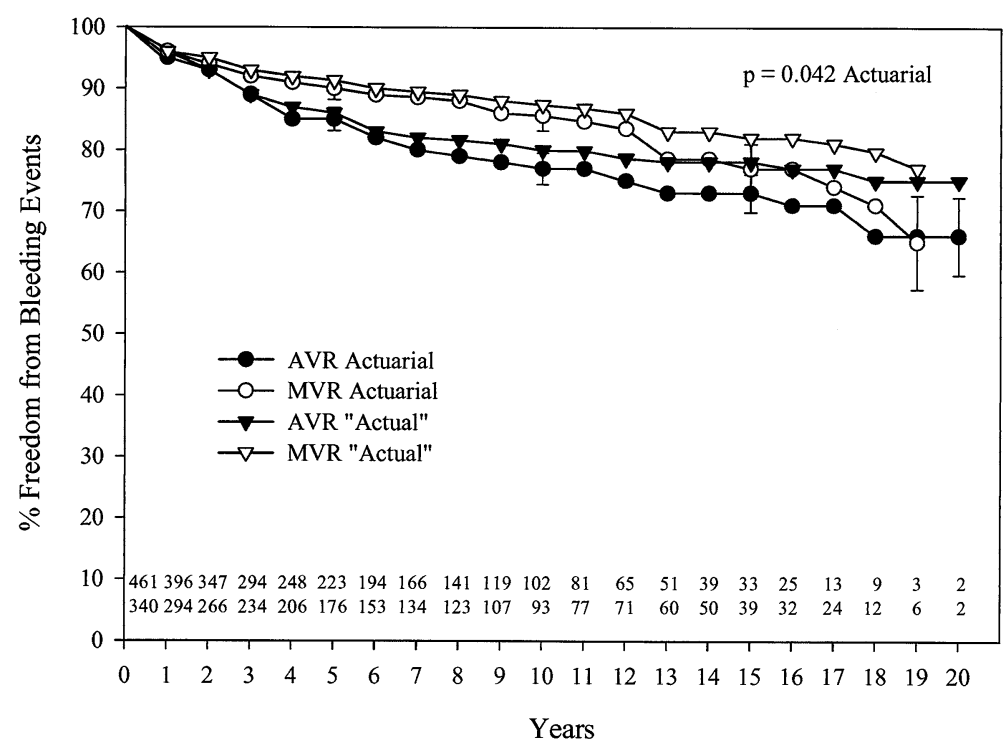

Figure 4. Actuarial and "actual" freedom from bleeding events after AVR and MVR.

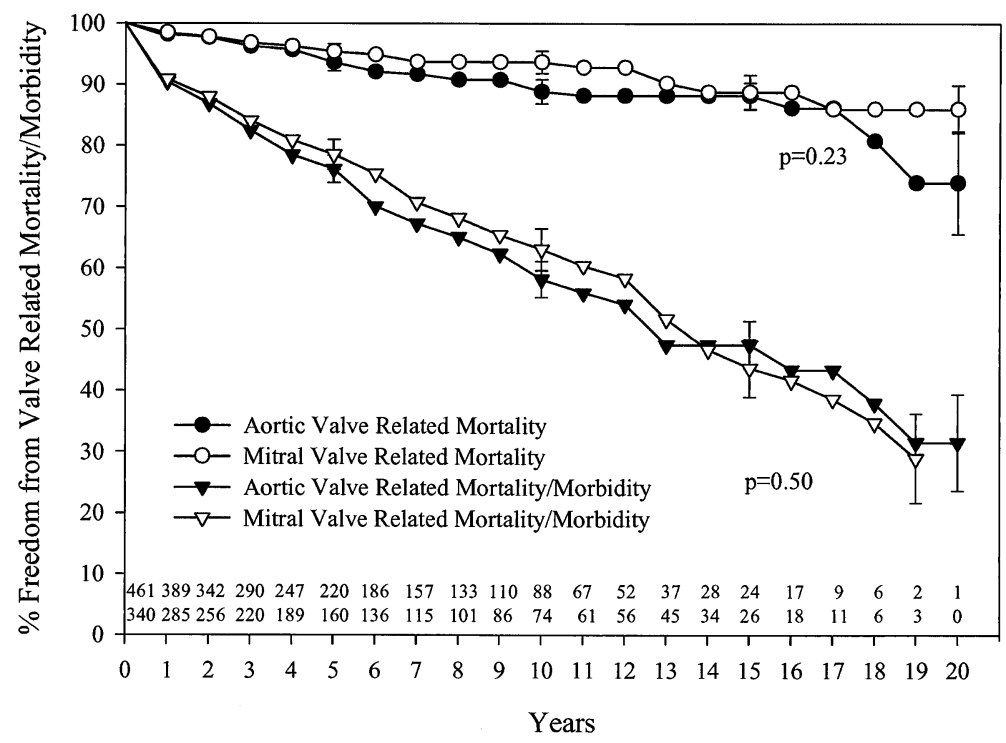

Figure 5. Actuarial and "actual" freedom from valve-related morbidity or mortality after AVR and MVR.

the remaining cohort of 767 patients (5638 patient-years) showed a significantly higher incidence of prosthetic valve endocarditis $(2.7 \%$ /patient-year vs $0.5 \% /$ patient-year, $P=$ $.02)$. All of these patients showed clinical and operative findings of endocarditis but were culture-negative. There were also nonsignificant trends toward increased reoperation $(2.7 \% /$ patient-year vs $0.7 \% /$ patient-year, $P=.053)$ and late death $(9.0 \% /$ patient-year vs $5.0 \% /$ patient-year, $P=$ 0.08) in the Silzone subset.

\section{Discussion}

The St Jude Medical bileaflet, pyrolytic carbon mechanical valve was introduced in 1977 and received approval from the Food and Drug Administration in 1982. We started using this valve while it was still an investigational device because of concerns about the durability of porcine valves and because of reports of structural complications in other mechanical valves. Both in vitro and in vivo studies demonstrated low gradients across the valve in both catheter- 
ization and echocardiographic evaluations. ${ }^{18,19}$ In our previous reports, ${ }^{1,2,7}$ we have observed, as have others, ${ }^{8-10}$ that the St Jude Medical mechanical prosthesis has superior durability (we have observed no structural failures), excellent hemodynamics, and a low incidence of thromboembolism. The current study examines 20 years of follow-up and reports our long-term experience with this valve. This data in this series was updated prospectively on an annual basis, which may result in a more complete account of complications due to better patient recall.

Operative mortality in the current series is $3.6 \%$ in the AVR group and $5.3 \%$ in the MVR group. These results compare favorably with other long-term studies of this prosthesis. ${ }^{8-10}$ Our data continue to show that preoperative patient characteristics such as age, previous valve replacement, cardiac function, and coronary disease may have a greater influence on operative mortality than the type of valve prosthesis implanted. Similar operative mortality is seen in other series of tissue and other commonly used mechanical valves. ${ }^{20-23}$

As other studies have observed, ${ }^{8-10}$ our data show that late death is usually unrelated to the prosthetic valve. Multivariable analysis demonstrated that the major independent variables impacting the long-term outcome in this patient population were high NYHA class, concomitant CABG, and increasing age in the both the AVR and MVR groups. In addition, in the AVR group African-American ethnicity emerged as a strong predictor of outcome. The reason for this is unclear. Previous studies have shown that AfricanAmerican ethnicity poses a significantly higher risk for hypertension, diabetes mellitus, and renal disease. ${ }^{24-26}$ Subgroup analysis within this cohort showed no significant differences between African-American and other ethnic groups with respect to these variables. Further analysis is required to identify factors that influence this predictor of outcome.

Thromboembolism remains a major complication after mechanical valve replacement. The linearized rate of thromboembolic complications in this series (AVR 2.0\%/patientyear, MVR 3.4\%/patient-year) is slightly lower than in our last report. This may reflect improved ability to reach and maintain acceptable anticoagulation status in our patients. The incidence of thromboembolism is comparable with other series of St Jude Medical mechanical valve replacement (0.8\% to $3.5 \%$ /patient-year). ${ }^{3-6,8-10}$ These thromboembolic rates are also comparable with the composite rates for other mechanical valves and tissue valves..$^{20-22}$

The incidence of anticoagulation-related bleeding complications has remained relatively low. The linearized rate was 2.5\%/patient-year (AVR) and 1.8\%/patient-year (MVR). This represents a considerable reduction in anticoagulant-related bleeding compared with our original 5-year study (AVR, 6.9\%/patient-year; MVR, 2.4\%/patient-year), ${ }^{1}$ a modest reduction compared with our 10-year report (AVR, 3.5\%/patient-year; MVR, 2.2\%/patient-year), ${ }^{2}$ and little difference from our 15-year report (AVR, 2.7\%/patient-year; MVR, $1.6 \%$ /patient-year). ${ }^{7}$ Other investigators have also observed a higher incidence of anticoagulationrelated bleeding after AVR compared with MVR. ${ }^{5}$ In general, we have been impressed with the low thromboembolic rate of the St Jude Medical mechanical prosthesis and have gradually lowered our target INR from 2.5 to 3.5 to 2.0 to 2.5 as have other groups, ${ }^{27,28}$ and this may account for the progressive decline in bleeding complications. Overall, however, thromboembolic and bleeding complications continue to be the Achilles' heel of mechanical valve replacement, with cumulative yearly rates of $4.5 \%$ for AVR and $5.3 \%$ for MVR, accounting for most of the valve-related morbidity seen in these patients.

The incidence of prosthetic valve endocarditis was quite low (AVR, 0.8\%/patient-year; MVR, 0.3\%/patient-year) and is similar to other series. ${ }^{8-10}$ It is interesting that after approximately 5 years, there is near complete freedom from endocarditis in both the aortic and mitral valve groups. It has been speculated that valve design, increased probability of prosthetic valve sterilization, and early incorporation of the cloth sewing ring by tissue in growth may offer some protection from late bacterial invasion.

Data from the 70 patients in this series who received Silzone-treated valves showed a higher linearized rate of prosthetic valve endocarditis. The association between Silzone treatment and valve-related complications is somewhat controversial but has been documented in other series. ${ }^{29-31}$ This valve was not used in our institution after December 1999 because of concerns regarding an increased rate of endocarditis and valve dehiscence.

Long-term follow-up of these patients has confirmed that undergoing prosthetic valve replacement does not confer a survival rate like that of the general population. To justify this within our data set, age-adjusted standard mortality rates $^{32}$ (SMR) were calculated for mitral and aortic valves combined. The expected number of deaths was propagated using the age-specific national death rates for the year $2000^{33}$ and the number of corresponding at risk patientyears for our valve population. Because the proportion of males to females in our study differed from that of the national population, a separate SMR was calculated for each gender. The results showed that our valve population had mortality rates significantly higher than those of the general population (men, SMR 4.3; women, SMR 5.4; $P<.0001$ ).

Although 20-year freedom from valve-related complications was only $32 \%$ (AVR) and 29\% (MVR), data from this study and others ${ }^{6}$ suggest that overall long-term survival after prosthetic valve replacement may be more strongly influenced by preexisting comorbidities prior to surgery than by the presence of a mechanical valve. As increasing 
numbers of elderly patients with more comorbidities undergo valve replacement, the influence of valve-related factors on mortality rate is likely to continue to decline compared with patient-related factors. In addition, with the improved durability of later generation tissue valves, the long-term results of mechanical valve replacement are also likely to be affected by increased use of bioprosthetic valves in younger patients.

In summary, this series of patients undergoing AVR and MVR with the St Jude Medical mechanical prosthesis with follow-up to 20 years confirms the excellent performance of this valve that we have documented in our earlier reports. In addition, the complete absence of structural valve deterioration makes the St Jude Medical mechanical heart valve prosthesis an excellent choice for patients who require mechanical prosthetic valve replacement.

\section{References}

1. Crawford FA Jr, Kratz JM, Sade RM, Stroud MR, Bartles DM. Aortic and mitral valve replacement with the St Jude Medical prosthesis. Ann Surg. 1984;199:753-61.

2. Kratz JM, Crawford FA Jr, Sade RM, Crumbley AJ III, Stroud MR. St Jude prosthesis for aortic and mitral valve replacement: a ten year experience. Ann Thorac Surg. 1993;56:462-8.

3. Arom KV, Nicoloff DM, Kersten TE, Lindsay WG, Northrup WF III. St Jude Medical prosthesis: valve-related deaths and complications. Ann Thorac Surg. 1987;43:591-8.

4. Arom KV, Nicoloff DM, Kersten TE, Northrup WF III, Lindsay WG, Emery RW. Ten years' experience with the St Jude Medical valve prosthesis. Ann Thorac Surg. 1989;47:831-7.

5. Czer LS, Chaux A, Matloff JM, et al. Ten-year experience with the St Jude Medical valve for primary valve replacement. J Thorac Cardiovasc Surg. 1990;100:44-55.

6. Khan S, Chaux A, Matloff J, et al. The St Jude Medical valve. Experience with 1000 cases. J Thorac Cardiovasc Surg. 1994;108: 1010-20.

7. Zellner JL, Kratz JM, Crumbley AJ III, et al. Long-term experience with the St Jude Medical valve prosthesis. Ann Thorac Surg. 1999;68: 1210-8.

8. Remadi JP, Baron O, Roussel C, et al. Isolated mitral valve replacement with St Jude Medical prosthesis: long-term results: a follow-up of 19 years. Circulation. 2001;103:1542-5.

9. Lund O, Nielsen SL, Arildsen H, Ilkjaer LB, Pilegaard HK. Standard aortic St Jude valve at 18 years: performance profile and determinants of outcome. Ann Thorac Surg. 2000;69:1459-65.

10. Emery RW, Arom KB, Kshettry VR, et al. Decision-making in the choice of heart valve for replacement in patients aged 60-70 years: twenty-year follow up of the St Jude Medical aortic valve prosthesis. J Heart Valve Dis. 2002;11(Suppl 1):S37-44.

11. Edmunds LH, Clark RE, Cohn LH, Miller DC, Weisel RD. Guidelines for reporting morbidity and mortality after cardiac valvular operations. Ann Thorac Surg. 1996;62:932-5.

12. Grunkemeier GL, Lambert LE, Bonchek LI, Starr A. An improved statistical method for assessing the results of an operation. Ann Thorac Surg. 1975;20:289-98.

13. Bodnar E, Wain WH, Haberman S. Assessment and comparison of the performance of cardiac valves. Ann Thorac Surg. 1982;34:146-56.

14. Kaplan EL, Meier P. Non-parametric estimation from incomplete observations. J Am Stat Assoc. 1958;53:457-81.

15. Grunkenmeier GL, Starr A. The expected lifetime of porcine valves. Ann Thorac Surg. 1989;48:317-8.

16. Hosmer DW, Lemeshow S. Applied logistic regression. New York: Wiley; 2000.

17. Cox DR, Oakes D. Analysis of survival data. London: Chapman and Hall; 1984.
18. Emery RW, Nicoloff DM. St Jude Medical cardiac valve prosthesis: in vitro studies. J Thorac Cardiovasc Surg. 1979;78:269-76.

19. Gray RJ, Chaux A, Matloff JM, et al. Bileaflet, tilting disc and porcine valve substitutes: in vivo hydrodynamic characteristics. J Am Coll Cardiol. 1984;3:321-7.

20. Khan SS, Trento A, DeRobertis M, et al. Twenty-year comparison of tissue and mechanical valve replacement. J Thorac Cardiovasc Surg. 2001;122:257-69.

21. Masters RG, Helou J, Pipe AL, Keon WJ. Comparative clinical outcomes with St Jude Medical, Medtronic Hall and CarboMedics mechanical heart valves. J Heart Valve Dis. 2001;10:403-9.

22. Butchart EG, Li HH, Payne N, Buchan K, Grunkemeier GL. Twenty years' experience with the Medtronic Hall valve. J Thorac Cardiovasc Surg. 2001;121:1090-100.

23. Anttila V, Heikkinen J, Biancari F, et al. A retrospective comparative study of aortic valve replacement with St Jude medical and MedtronicHall prostheses: a 20-year follow-up study. Scand Cardiovasc J. 2002;36:53-9.

24. Ibrahim SA. Hypertension and medication adherence among African Americans: a potential factor in cardiovascular disparities. J Natl Med Assoc. 2003;95:28-9.

25. Khurana C, Rosenbaum CG, Howard BV, et al. Coronary artery calcification in black and white women. Am Heart J. 2003;145:724-9.

26. Adeniyi A, Folsom AR, Brancati FL, Desvorieux M, Pnakow JS, Taylor H. Incidence and risk factors for cardiovascular disease in African Americans with diabetes: the Atherosclerosis Risk in Communities (ARIC) study. J Natl Med Assoc. 2002;94:1025-35.

27. Arom KV, Emery RW, Nicoloff DM, Petersen RJ. Anticoagulant related complications in elderly patients with St Jude mechanical valve prostheses. J Heart Valve Dis. 1996;5:505-10.

28. Horstkotte D, Schulte HD, Bircks W, Strauer BE. Lower intensity anticoagulation therapy results in lower complication rates with the $\mathrm{St}$ Jude Medical prosthesis. J Thorac Cardiovasc Surg. 1994;107:113645 .

29. Tozzi P, Al-Darweesh A, Vogt P, Stumpe F. Silver-coated prosthetic heart valve: a double-bladed weapon. Eur J Cardiothorac Surg. 2001; 19:729-31.

30. Sepelt RG, Vazquez-Jimenez JF, Seipelt IM, et al. The St Jude "Silzone" valve: midterm results in treatment of active endocarditis. Ann Thorac Surg. 2001;72:758-62.

31. Herijgers P, Herregods MC, Vandeplas A, Meyns B, Flameng W. Silzone coating and paravalvular leak: an independent, randomized study. J Heart Valve Dis. 2001;10:712-5.

32. Rosner B. Fundamentals of biostatistics. 5th ed. Belmont: Duxbury Press; 2000.

33. Arias E, Smith BL. Deaths: Preliminary Data for 2001. National vital statistics reports. Hyattsville, Maryland: National Center for Health Statistics. 2003;51(5).

\section{Discussion}

Dr Alfredo Trento (Los Angeles, Calif). This is an important retrospective review because it further conclusively supports with a longer follow-up the data on the St Jude Medical valve, which I think can be translated with minor differences to the other bileaflet valves.

Two years ago we published our 20-year comparison between St Jude Medical and tissue valves. There were 670 St Jude Medical valves and 720 tissue valves in the aortic position, about $500 \mathrm{St}$ Jude Medical valves and 400 tissue valves in the mitral position. The mean age of patients with the St Jude Medical valve was almost 10 years greater. The 10 - and 20-year actuarial survival for all the patients with mechanical and biological prostheses was similar to that presented here by you today.

Freedom from thromboembolic events was also similar for both St Jude Medical and tissue valves in both aortic and mitral position. Freedom from hemorrhage was also similar. The only difference is that in the aortic position, biological prostheses fared much 


\begin{tabular}{ll}
$\begin{array}{l}\text { Appendix. Variables examined for association } \\
\text { operative mortality and late death }\end{array}$ \\
\hline Operative mortality & \multicolumn{1}{c}{ Late survival } \\
\hline Aortic valves & $\begin{array}{c}\text { Aortic valves } \\
\text { Gender }\end{array}$ \\
Age at operation & Age at operation \\
Body surface area & Year of surgery \\
Year of surgery & Race \\
Race & Valve size $<21$ mm \\
Valve size 19 mm & Effective orifice area $<2.59$ \\
CABG 3 or more vessels & Effective orifice area index \\
Reoperation & Associated CABG \\
Preoperative NYHA class IV & Reoperation \\
Lesion (aortic stenosis) & Preoperative NYHA class III or IV \\
& Lesion (aortic stenosis) \\
Mitral valves & Mitral valves \\
Gender & Gender \\
Age at operation & Age at operation \\
Body surface area & Year of surgery \\
Year of surgery & Race \\
Race & Valve size \\
Valve size 19 mm & Associated CABG \\
CABG 3 or more vessels & Reoperation \\
Reoperation & Preoperative NYHA class III or IV \\
Preoperative NYHA class IV & Lesion (mitral insufficiency) \\
Lesion (mitral insufficiency) & Ischemic etiology \\
Ischemic etiology & \\
\hline
\end{tabular}

NYHA, New York Heart Association; CABG, coronary artery bypass grafting.

better, with a freedom from hemorrhage of $94 \%$ and $92 \%$ at 10 and 20 years, respectively.

We have also learned from other retrospective studies, as well from the 2 randomized studies that are published, that in general, long-term survival is not influenced by the type of valve that we use, mechanical or biologic, but by other factors, as you mentioned, like age, coronary artery disease, New York Heart Association class, diabetes, and finally, and probably, valve to patient size mismatch.

In view of this background, justifiably or not, over the past 10 years, in the aortic position we have reduced the use of St Jude Medical valves from 55\% in 1991 to less than $20 \%$ in 2002. In the mitral position the same things happened in favor of mitral valve repair.

Quality of life, freedom from warfarin, and increased mobility of the patient population, which makes follow-up more difficult, have steered patients and physicians away from warfarin. Has your experience been similar on the choice of valves? Could you also relate the thromboembolic and hemorrhagic complications to the patient's INR when they happen? Was the patient's INR out of range?

Now, the most important issue is the warfarin therapy. How low do you think you can push the INR? Do you think we can have a safe anticoagulation for the aortic valve with an INR between 1.5 and 2 for the aortic position and an INR around 2 for the mitral position? That would make warfarin therapy much more attractive.

Dr Ikonomidis (Charleston, SC). Thank you, Dr Trento, for those insightful comments and questions. With regard to compar- ing mechanical valves to tissue valves, what we have observed is what has generally been observed in most studies, namely that the durability of mechanical valves exceeds that of tissue valves, whereas tissue valves show superior freedom from thromboembolic and bleeding complications.

As far as relating thromboembolic and hemorrhagic complications to the patient's INR, we didn't specifically relate the incidence of the complication to the INR, but that would be something that worth looking at. As far as decreasing the targeted INR is concerned, despite the fact that we have decreased the INR in our institution, this has not resulted in an increase in thromboembolic rates; in fact, it has still dropped to a small extent. Therefore, at the present time we feel that our current target INRs are safe.

Dr Kit V. Arom (Minneapolis, Minn). I rise to congratulate the group from Charleston for their excellent long-term follow-ups, particularly with $98 \%$ completed. We, too, in Minneapolis, after Demetre Nicoloff implanted the first valve in 1977, have followed these people up to 20 years. At that time with $95.4 \%$ complete (21,342 patient years), we had 3937 patients available for the study. About 1300 of the patients were dead at that time or approximately one third of them.

The causes of death were $4.5 \%$ valve-related, $4 \%$ related to anticoagulation. The rest of them died from ongoing atherosclerosis and heart failure (48\%). Linearized rate (percent per patientyear) included 1.24 for thromboembolism (TE), 1.00 for bleeding, 0.1 for perivalvular leak, 0.18 for prosthetic endocarditis, and valve thrombosis was 0.09 .

If we translate this into actuarial analysis, we obtained results similar to yours, except in 2 areas. One is that at the end of 20 years our aortic valve had better survival rate than the mitral valve, being about $44 \%$, comparing with about $33 \%$ for the mitral valve.

And the other area was the incidence free from bleeding and TE. There was about $82 \%$ incidence free from bleeding and $70 \%$ free from TE. If I remember correctly, this is quite different than yours, which it is about $60 \%$.

We did lower the intensity of anticoagulation in 1985 by keeping the INR between 1.8 and 2.5 for AVR, 2.5 and 3.2 for MVR.

Dr Trento has suggested lowering intensity of anticoagulation, which I agree with. At the present time we still using a slightly lower intensity than what you just described, and I think this could be the reason why we see a slightly better TE and bleeding rate.

Dr Ikonomidis. How did you conduct the follow-up on your patients?

Dr Arom. Our follow-up is not quite as good as yours, which is being done yearly. We hope, however, that we can use the same approach that you do. In 1985, we also instructed the cardiologist and family physician to stop using prothrombin values and to have the INR strictly within the range that I have mentioned. I really believe that this approach has contributed to our recent outcomes.

Dr Ikonomidis. The less aggressive warfarin dosing that you described may help address your improved freedom from TE and bleeding compared with our series. In addition, conducting follow-up over longer time intervals may cause patients to forget some events, effectively increasing the documented freedom from TE and bleeding complications.

As for addressing the flip in terms of aortic and mitral valve survival, I think that this discrepancy may reflect inherent differ- 
ences in the population as they relate to severity of comorbid factors such as hypertension, left ventricular hypertrophy, and perhaps even compliance with medications.

Dr W. R. Eric Jamieson (Vancouver, British Columbia, Can$a d a$ ). Congratulations on an excellent study. I just have 2 short questions. You shared with us your linearized occurrence rates for aortic and mitral valves. Could you share with us the linearized rates for major embolisms, including Reversible Ischemic Neurologic Deficits, and comment also on early and late events, because many patient mechanical populations can have major events in the first 30 days.

My second question is related: have you looked at actual versus actuarial freedoms when you assess the composites of complications, morbidity, mortality, and reoperation, which are probably better parameters when you are counseling patients to have a mechanical or any prosthesis?

Dr Ikonomidis. I am sorry, Dr Jamieson, can you repeat the second question?

Dr Jamieson. The concept of using actual freedoms compared with actuarial freedoms, which are better parameters to use when counseling patients as to which prosthesis they should have.
Dr Ikonomidis. All of the nondeath outcomes were analyzed by cumulative incidence analysis. I did not include them here in this presentation for purposes of simplicity but in all end points measured, the cumulative incidence curves were all shifted upward compared with the actuarial freedom curves, as one would expect. With regard to neurologic events, approximately one third were early and then the remaining two thirds occurred later on.

Dr Mohammed A. Quader (Cleveland, Ohio). Congratulations on your excellent presentation of this valuable data. I would like to ask you a question about the use of 19-mm valves. Fifteen percent of the patients had the 19-mm valve placed, and multivariate analysis has shown that there is an increased risk of death with that. Has there been a trend toward not using this valve more frequently in the recent past?

Also, have you looked for patient-prosthesis mismatch in that group of patients?

Dr Ikonomidis. We have trended toward not using 19-mm valves as much as possible. As far as patient-prosthesis mismatch is concerned, neither EOA nor EOA index were found to be multivariate predictors of death. 